\title{
Electromagnetic contribution to the resilience improvement against the Vrancea intermediate depth earthquakes, Romania
}

\author{
Dragoș Armand Stănică ${ }^{1}$, Dumitru Stănică ${ }^{*}, 1$, Monica Valeca ${ }^{2}$, Ștefan Iordache ${ }^{3}$ \\ (1) Institute of Geodynamics of the Romanian Academy, Jean-Lois Calderon, Str. 19-21, Bucharest, Romania, \\ www.geodin.ro, armand@geodin.ro,dstanica@geodin.ro \\ (2) Institute of Nuclear Research, Câmpului Str.1, RO-115400, Mioveni - Argeș, Romania, www.nuclear.ro, \\ monica.valeca@nuclear.ro \\ (3) University of Bucharest, Faculty of Geography, N. Bălcescu Blvd. 1, Romania, www.unibuc.ro, \\ st.iordache@gmail.ro
}

Article history: received January 18, 2019; accepted January 27, 2020

\begin{abstract}
In this paper we used the geomagnetic data, collected in real time on the intervals AugustSeptember and November-December, 2016, to emphasize possible relationships between the anomalous behavior of the normalized function Bzn and the both M5.7 and M5.6 earthquakes, generated at $72 \mathrm{~km}$ and, respectively $71 \mathrm{~km}$ depth, in the seismic active Vrancea zone on September 24 and December 28, 2016. Daily mean distributions of the Bzn and its standard deviation (SD) are obtained for the both time-intervals, in the ULF frequency range $0.001 \mathrm{~Hz}-0.0083 \mathrm{~Hz}$, by using the FFT band-pass filtering. We investigate the singularities of the pre-seismic anomalous signals related to the M5.7 and M5.6 earthquakes applying a statistical analysis based on a standardized random variable equation, and the results are presented as $\mathrm{Bz}^{*}$ time series performed on the new time intervals 1-30 September and 1-31 December, 2016. Finally, two pre-seismic anomalous signals are observed: first one on September 21, with values greater than $5 \mathrm{SD}$, what means a lead time of 3 days before the onset of M5.7 earthquake; the second one, with values larger than 4 SD, which was identified on December 21 with 7 days prior to M5.6earhquake. In conclusion, as the work-station has specific programs for data processing, analyses and real time (daily) data display on the institute website, it may be used as an early warning system able to provide useful information for resilience improvement against the Vrancea intermediate depth seismicity.
\end{abstract}

Keywords: electromagnetic pre-seismic signals, Mw 5.7 and Mw 5.6 earthquakes, Vrancea zone, Romania, resilience improvement.

\section{Introduction}

It is well known that the assessment of natural hazard and risk generally aims at analyzing potential impact of specific processes to a rather well balanced system, in order to emphasize to what extent it might be affected in the future. In this context, the application of the electromagnetic (EM) methods to identify the precursory 


\section{Dragoș Armand Stănică et al.}

parameters related to the earthquakes could be very useful tool for the resilience improvement. Thus, the basic features of the earthquake preparation stage related to the EM pre-seismic anomalous signals have been analyzed, and some of them are presented farther on. According to Gufeld et al. [1999], the degassing model of the Earth could be one of main actors controlling seismicity processes and energy transfer in the lithosphere. This model, based on laboratory experiments, includes the ascending diffusion effect of helium, hydrogen and possible other gases belonging to the crystalline structure of the rocks. Although, the origin of the ULF geomagnetic signal is not well-known yet, the following generation mechanisms may be also considered: a) Magneto-hydrodynamic effect, which supposes that the conducting fluid flow, in the presence of a magnetic field, generates a secondary induced component [Sasay, 1991]; b) piezo-magnetic effect, based on the idea that a secondary magnetic field is induced by changes in ferromagnetic rocks magnetization, due to an applied stress [Fitterman, 1978]; c) Electrokinetic effect, based on electric currents flow at the interface solid-liquid boundaries, which in turn may generate a magnetic field [Fitterman, 1978; Varotsos at al., 1986]; d) Piezo-stimulated current and current generated by charged dislocation [Varotsos at al., 1986]. Another concept [Freund, et al.,1999, Freund, 2000], according to which the most of rock forming the mineral composing lithosphere can emanate molecular hydrogen, as result of the impurity of $\mathrm{OH}^{-}$in their crystalline structures. Some authors [Nomikos et al. 1997; Nomikos and Vallianatos, 1997, 1998; Vallianatos and Tzanis, 1998, 1999; Vallianatos et al. 2004; Tramutoli et al. 2005;Varotsos, 2005; Yen, et al., 2004 and Ouzounov et al., 2007] suggest that in the Earth's lithosphere, the well conducting channels (deep faults) do exist and may generate continuous intersecting geotectonic systems, so that the research on the relation between spatial - temporal changes of the electrical conductivity and seismic events play an important role in hazard evaluation. Possible scaling laws between the electric earthquake precursors and earthquake magnitude, as well as between spectral properties and ULF signals have been done by Vallianatos and A. Tzanis, [2003 and 2004]. It was just demonstrated [Ismail-Zadeh et al., 2000; Stanica et al., 2004; Stanica and Stanica, 2012], that before an earthquake initiation, the high stress reached into the Vrancea seismogenic volume may generate dehydration of the rocks and fracturing processes, followed by release of electric charge which are propagated along the faulting systems, acting as high conductive path known as the Carpathian electrical conductivity anomaly (CECA), what lead to resistivity changes [Pinna et al., 1992]. On the base of the EM parameters carried out throughout the ULF range, these changes of resistivity will be analyzed in this paper [Stanica and Stanica, 2010, 2011; and Stanica et.al, 2015]. Taking into account that the seismic-active Vrancea zone is one of the "hot" subjects in this direction, a specific EM methodology able to emphasize the short-term EM precursory parameters, associated to the two intermediate depth earthquakes of Mw 5.7 and Mw 5.6 generated in 2016, on September 24 and December 28, respectively, will be applied. According to the EM information acquired in a span of several years correlated with the Vrancea seismicity, it was relieved that: (i) Some days before the earthquake occurrence, the daily mean distribution of the EM parameters has an anomalous behavior marked by a significant increase/decrease value versus its normal trend identified in non-seismic conditions; (ii) Applying a statistical analysis, based on the standardized random variable equation, it was created possibility to identify with high accuracy the pre-seismic anomalous intervals, some days before the onset of the both seismic events (Mw 5.7 and Mw 5.6); (iii) The topic of resilience could not be fully understood analyzing only by one methodology or by disciplines separately, due to the inherent complexity of the Vrancea earthquakes generation mechanisms and the need to solve societal problems. Consequently, in this paper some innovative contributions to the resilience improvement against the intermediate depth earthquakes by using EM methodology will be promoted.

\section{Geodynamics and seismicity of the Vrancea zone}

\subsection{Geodynamic models}

The seismicity of the Vrancea region, placed in the Carpathians bending zone, is characterized by the occurrence of intermediate depth earthquakes in a specific narrow epicentral area and hypocentral volume and, starting with the end of the last century up to now, several tomographic images have been elaborated. Inverting teleseismic events recorded by the Romanian earthquake network, a low velocity structure situated between 40 and $60 \mathrm{~km}$ depth have been identified [Oncescu et al., 1984]. 


\section{Resilience improvement to Vrancea earthquake}

High velocity material situated between 80 and $170 \mathrm{~km}$ depth, representing the level of intermediate depth seismicity, was located [Oncescu, 1984; Koch, 1985].

The oceanic lithosphere breaking off took place after the beginning of the collision and thus the resulting slab, almost sub-vertical, have been emphasized [Constantinescu and Enescu, 1984].

Analyzing the seismic behavior of the Vrancea zone, a model based on the existence of two active zones located at depths of $80-110 \mathrm{~km}$ and 120-170 km has been proposed [Trifu and Radulian,1989], and the both zones characterized by local stress inhomogeneity are capable of generating large earthquakes.

An image of the entire Mediterranean area including SE Europe reveals very important feature as a phenomenon of slab detachment in Thyrrenian area, and weak indications of slab detachment are also visible for the Carpathian Arc Bend [Wortel and Spakman, 1992; Spakman et al., 1993].

With a larger set of regional earthquakes and records it was confirmed that the intermediate seismogenic volume is characterized by high velocity [Fan et al., 1998].

Taking into consideration that the geometry of the subduction zone was not unequivocally defined, four possible configurations for the Vrancea zone are proposed (CRC Group 461, 1999): (a) subduction beneath the suture zone; (b) subduction beneath the fore-deep area; (c) two interacting subduction zones; (d) subduction beneath the suture, followed by delamination.

The results carried out by magnetotelluric tomography [Stanica et al., 2004; Stanica and Stanica, 2012] emphasized: (a) a continental origin for the seismogenic body; (b) the changes with depth of its strike orientation could be the result of a geodynamic torsion process.

\subsection{Vrancea seismicity and CECA}

The Vrancea zone is located at the Carpathian bending area being bounded to the East by the East European Platform (EEP), to the South by the Moesian Platform (MP), and westwards by the Transylvanian Basin (TB). The intermediate depth earthquakes are placed in a well-defined volume $70 \mathrm{~km}$ long, $30 \mathrm{~km}$ wide, about $220 \mathrm{~km}$ high, and the epicentral area is delimited at NW and SE by CECA. The frequency of Vrancea earthquakes can be assessed from the available catalogues, and their occurrence is about 2-10 events/month of magnitude $\mathrm{M}<4$ and, about 1-4 strong events/century of magnitude $\mathrm{M} \geq 7$. The ruptured zones in seismogenic volume jump from 150-180 km for the Mw 7.8 earthquake in 1940, to $90-110 \mathrm{~km}$ for the $\mathrm{Mw} 7.5$ earthquake in 1977, to 130-150 km for the Mw 7.2 earthquake in 1986, to $70-90 \mathrm{~km}$ for Mw 6.9 earthquake in 1990 . The crustal activity is weak, often occurred in clusters and mainly located in the depth interval of $10-40 \mathrm{~km}$.

CECA represents a conglomerate of sedimentary rocks, filled with hot highly-mineralized pore fluids, formed only at a contact zone between two continental plates and it is also quite possible that the geoelectric parameters remain fairly constant throughout its entire length [Pinna et al., 1992; Stanica and Stanica, 2010, 2011, 2012; Stanica et al., 2018].

The Mw 5.7 and M5.6 earthquakes struck the Vrancea zone on September 24 and December 28, 2016. Their epicenters have been located at the geographic coordinates $45: 71 \mathrm{~N} ; 26.62 \mathrm{E}$ and $45.72 \mathrm{~N} ; 26.61 \mathrm{E}$, with a focal depth at 92 and $91 \mathrm{~km}$, being placed at about $150 \mathrm{~km} \mathrm{NE}$ of Bucharest, as both of them have been determined by the Euro-Mediterranean Seismic Centre (http://www.emsc-csem.org). Although the two earthquakes were moderate as magnitude, they have been felt in Bucharest city and create panic through its inhabitants.

\section{Methodology and results}

\subsection{Base relations of the electromagnetic precursors}

It was just demonstrated that at the Earth' surface, the vertical geomagnetic component (Bz) expresses totally a secondary field and its existence represents an immediate indicator of the lateral inhomogeneities. Furthermore, for a $2 \mathrm{D}$ geoelectrical structure, $\mathrm{Bz}$ is essentially produced by the horizontal geomagnetic component perpendicular to the geoelectric strike $\left(\mathrm{B}^{\perp}\right)$ and, as a sequence, the normalized function Bzn having the form (1): 


\section{Dragoș Armand Stănică et al.}

$$
B z n(f)=\frac{B z(f)}{B_{\perp}(f)}
$$

must be time invariant and it becomes unstable when the geodynamic processes are associated with the resistivity changes, due to the intermediate-depth seismicity in Vrancea zone [Word, et al., 1970; Stanica and Stanica, 2010].

To explain the connection between the earthquake generation and the anomalous values of the Bzn (f), the following relations that allow its assessment in terms of resistivity are introduced:

$$
\rho z(f)=\frac{1}{5 f}\left|\frac{E_{I I}(f)}{B z(f)}\right|^{2} \text { and } \rho_{\mathrm{II}}(f)=\frac{1}{5 f}\left|\frac{E_{I I}(f)}{B_{\perp}(f)}\right|^{2}
$$

where: $\rho z$ is vertical resistivity $\left[\mathrm{VmA}^{-1}\right], \mathrm{E}_{\mathrm{II}}$ is electric field parallel to the geoelectric strike $\left[\mathrm{Vm}^{-1}\right]$; $\rho_{\mathrm{II}}$ is resistivity parallel to the 2D structure [VmA ${ }^{-1}$ ] and $\mathrm{f}$ is frequency [Hz].

Based on the relations (2), the normalized function Bzn may be writen as:

$$
|B z n(f)|=\sqrt{\frac{\rho_{\mathrm{II}}(f)}{\rho z(f)}}
$$

With the relation (3), it is demonstrated that normalized function Bzn may be associated with the resistivity changes before the onset of the seismic event and, consequently, Bzn may be used to emphasize the pre-seismic EM anomalies associated with the seismic activity in Vrancea.

To find the adequate monitoring site (on the 2D geoelectric structure), we have taken into account that between the electric components (Ex and Ey) and magnetic components (Bx and By) of the natural EM field there is the following relation of interdependence:

$$
\left(\begin{array}{l}
E x \\
\text { Ey }
\end{array}\right)=\left(\begin{array}{ll}
\text { Zxx } & \text { Zxy } \\
\text { Zyy } & \text { Zyy }
\end{array}\right) \cdot\left(\begin{array}{l}
\text { Bx } \\
\text { By }
\end{array}\right)
$$

where: Ex, Ey and Bx, By, are Cartesian components of electric $\left[\mathrm{Vm}^{-1}\right]$ and magnetic $\left[\mathrm{Vsm}^{-1}\right]$ fields; Zxx, Zxy, Zyx, Zyy are the tensor impedance elements $\left[\mathrm{VA}^{-1}\right]$. Then, to identify a $2 \mathrm{D}$ geoelectric structure, in addition to the condition that dimensionality parameter skewness $<0.3$ [Stanica and Stanica, 2010], the following conditions must be fulfilled:

$$
\begin{aligned}
& Z x x=-Z y y \\
& Z x y \neq-Z y x
\end{aligned}
$$

With the other words, for a 2D geoelectric structure the electric and magnetic fields are mutually orthogonal and Bzn may be associated with E-polarization mode, which in terms of the electromagnetic field components Ex, By, and $\mathrm{Bz}$, describe electrical currents that are propagated parallel to strike (x direction), as it is shown in relation (6):

$$
\partial \mathrm{Ex} / \partial \mathrm{y}=\partial \mathrm{Bz} / \partial \mathrm{t}=\mathrm{i} w \mathrm{Bz} ; \quad \partial \mathrm{Ex} / \partial \mathrm{z}=\partial \mathrm{By} / \partial \mathrm{t}=-\mathrm{i} w \mathrm{By} ; \quad \partial \mathrm{Bz} / \partial \mathrm{y}-\partial \mathrm{By} / \partial \mathrm{z}=\mu \sigma \mathrm{Ex},
$$

where: $w$ is angular frequency $\left[\mathrm{s}^{-1}\right], \mu$ is magnetic permeability $\left[\mathrm{VsA}^{-1} \mathrm{~m}^{-1}=\mathrm{Hm}^{-1}\right], \sigma$ is conductivity $\left[\mathrm{Sm}^{-1}\right], \mathrm{Ex}$ is electric field parallel to strike $\left[\mathrm{Vm}^{-1}\right]$.

To satisfy the relations (1) and (6), the GOPS was placed on the CECA at about $100 \mathrm{~km}$ far from the seismic active Vrancea zone.

The reliability level of the EM methodology, related to the seismic activity, could be verified by analyzing the daily mean distribution of the Bzn in correlation with intermediate depth earthquakes ( $\mathrm{Mw} \geq 5.0)$ for long time intervals.

To investigate the range effect of stain-related the EM precursors, in this paper we used the relation given by [Morgunov and Malzev, 2007] and, consequently, the radius of the preparation zone for the two earthquakes (Mw 5.7 and Mw 5.6) was estimated to be about $300 \mathrm{~km}$. As the distance between GOPS and earthquakes epicenter is $100 \mathrm{~km}$, the existence condition of the EM precursors is fulfilled. 


\subsection{Data collection and processing}

The ground-based monitoring system for EM data collection (Figure 1) is installed at GOPS and consists of: - magnetotelluric (MT) system (MTU data logger, three magnetic induction coils Hx, Hy and Hz and nonpolarizable electric sensors) is used to validate the frequency range for a 2D geoelectric structure;

- geomagnetic system (MAG03DAM data logger and three-axes fluxgate magnetic sensor) suitable for the geomagnetic time series Bx, By and Bz collection with a sampling rate of $60 \mathrm{~s}$;

- computer with programs dedicated to the data acquisition, storage and daily transfer to the Institute of Geodynamics of the Romanian Academy (IG-RA).

The automatic system for real-time data processing and analysis is installed at IG-RA and has the following components:

- computer (server) used for receive and storage the geomagnetic data records;

- work-station with specific programs for data processing, analyzing and display results every day on the institute webpage.

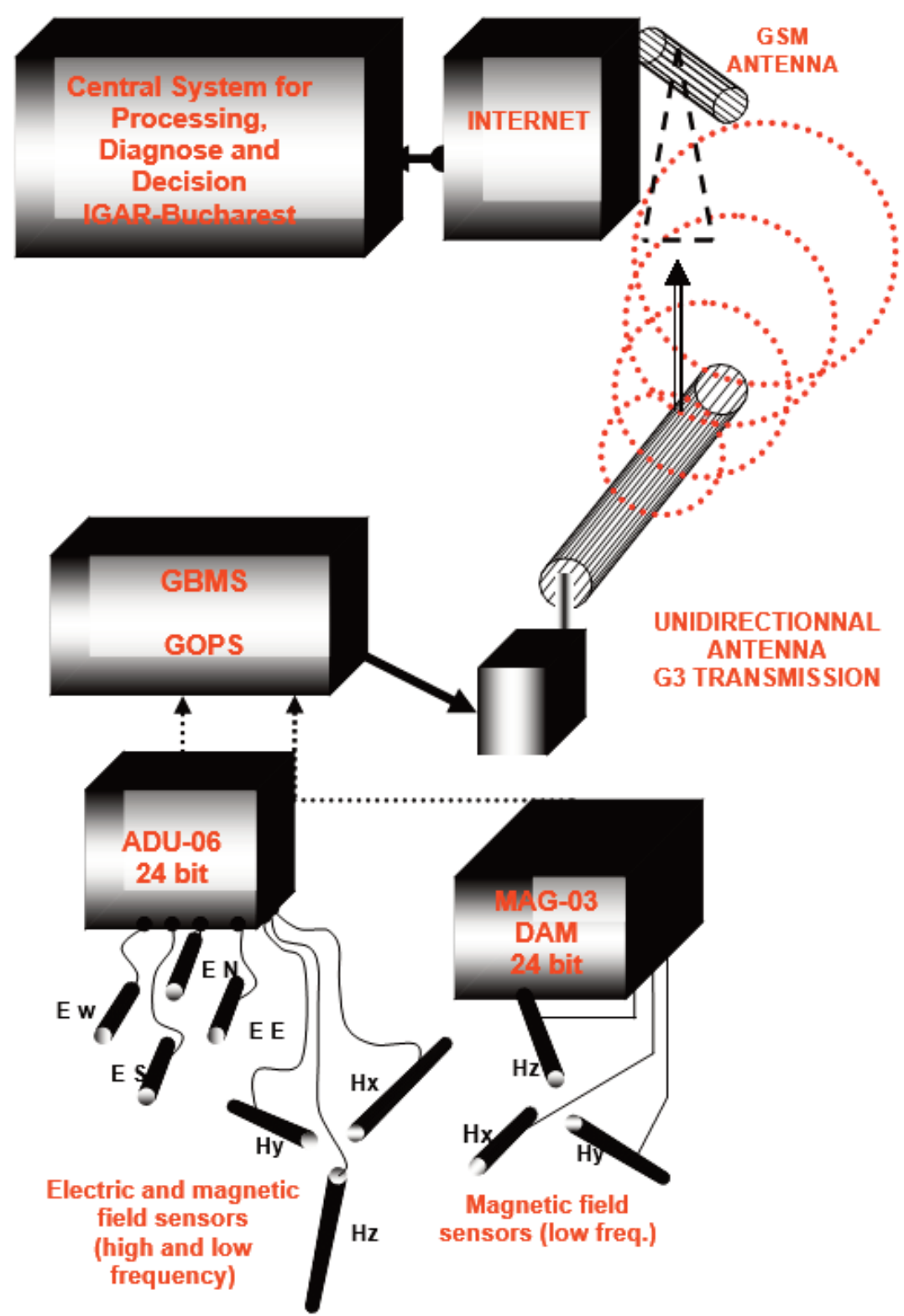

Figure 1. EM monitoring system, data transfer and central computer for real-time data processing and analysis. 


\section{Dragoș Armand Stănică et al.}

In this study, the daily mean distributions of the normalized function Bzn and its standard deviation (SD) are computed on the span of time intervals 01-30 September and 01-30 December, 2016, by using the following procedures:

- FFT Band-pass filtering (FFT-BPF) analysis in the ULF range applied to Bzn time series, for two successive time windows of 1024 samples, with about 30\% overlapping on 1440 data acquired each day, see Figure 2 and Table 1;

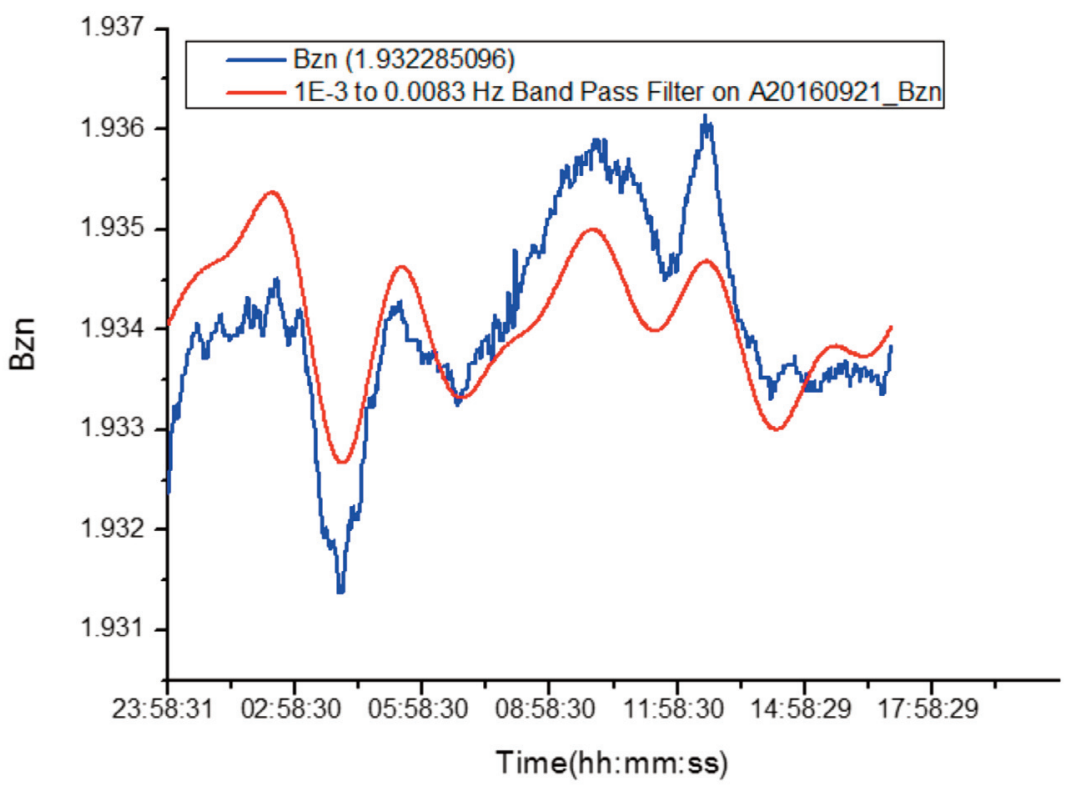

Figure 2. Graphs with FFT - BPF (red line) applied on the Bzn time series (blue line) for a time windows of 1024 samples $(\Delta \mathrm{t}=60 \mathrm{~s})$ recorded on September 21, 2016.

\begin{tabular}{|c|c|c|c|c|c|c|c|}
\hline $\mathrm{B}^{\perp}\left[\mu^{\top} \mathrm{T}\right]$ & $\mathrm{Bz}[\boldsymbol{\mu T}]$ & $\operatorname{Bzn}[\mu \mathrm{TT}]$ & Bzn (mean) & SD & $\underset{\text { (FFT-BPF) }}{\text { Bzn }}$ & $\begin{array}{c}\text { Bzn } \\
\text { (FFT-BPF) } \\
\text { (mean) }\end{array}$ & SD \\
\hline 22.193 & 42.888 & 1.9325 & 1.933 & 0.0003 & 1.9341 & 1.934 & 0.0001 \\
\hline 22.192 & 42.888 & 1.9326 & & & 1.9341 & & \\
\hline 22.189 & 42.887 & 1.9328 & & & 1.9341 & & \\
\hline 22.187 & 42.887 & 1.933 & & & 1.9341 & & \\
\hline 22.187 & 42.887 & 1.933 & & & 1.9341 & & \\
\hline 22.186 & 42.887 & 1.933 & & & 1.9341 & & \\
\hline 22.185 & 42.887 & 1.9331 & & & 1.9341 & & \\
\hline 22.184 & 42.887 & 1.9332 & & & 1.9342 & & \\
\hline 22.184 & 42.887 & 1.9332 & & & 1.9342 & & \\
\hline 22.184 & 42.887 & 1.9332 & & & 1.9342 & & \\
\hline 22.184 & 42.887 & 1.9332 & & & 1.9342 & & \\
\hline 22.184 & 42.886 & 1.9332 & & & 1.9342 & & \\
\hline 22.185 & 42.886 & 1.9332 & & & 1.9342 & & \\
\hline 22.184 & 42.886 & 1.9331 & & & 1.9342 & & \\
\hline 22.183 & 42.886 & 1.93334 & & & 1.9343 & & \\
\hline 22.183 & 42.886 & 1.9334 & & & 1.9343 & & \\
\hline 22.182 & 42.886 & 1.9335 & & & 1.9343 & & \\
\hline
\end{tabular}

Table 1. Time series of B`, Bz, Bzn, Bzn (mean), SD, Bzn (FFT-BPF), Bzn (FFT-BPF) (mean), SD obtained only for 17 samples $(\Delta t=60$ s) on September 21, 2016 
- a statistical analysis based on the standardized random variable Equation (7) was applied for a clear evidence of the pre-seismic anomalies emphasized by the Bzn time series and to eliminate the seasonal variations (Stanica et.al. 2015).

$$
\mathrm{Bzn}^{*}=(\mathrm{X}-\mathrm{Y}) / \mathrm{W}
$$

Where:

- $\mathrm{X}$ is the mean value of the normalized function Bzn obtained for 1day;

- $\mathrm{Y}$ is 30 days running average of Bzn carried out before $\mathrm{X}$;

- $\mathrm{W}$ is 30 days running average of SD carried out before $\mathrm{X}$;

- Bzn* represents the threshold for anomaly using SD.

\subsection{Results and discussions}

According to relation (1) and Equation (6), the daily mean distributions of Bzn and Bzn* obtained on the frequency range $1 \mathrm{E}-3 \mathrm{~Hz}$ to $0.0083 \mathrm{~Hz}$, by using the FFT- BPF, should be constants or have small variations in nonseismic conditions and have consistent anomalous variations versus their normal trend, some days before the onset the both seismic events (Mw 5.7 and Mw 5.6). Thus, as final results, this paper presents the contribution to the development of the pre-seismic EM methodology, by using the geomagnetic data carried out for the two intervals:

a) September 2016 with the following graphs:

- Daily mean distributions of Bzn (Figure 3);

$-\mathrm{B}^{\perp}$ and $\mathrm{Bz}$ time series recorded for 7 days (Figure 4);

- Bzn* time series, represented in absolute values (Figure 5).

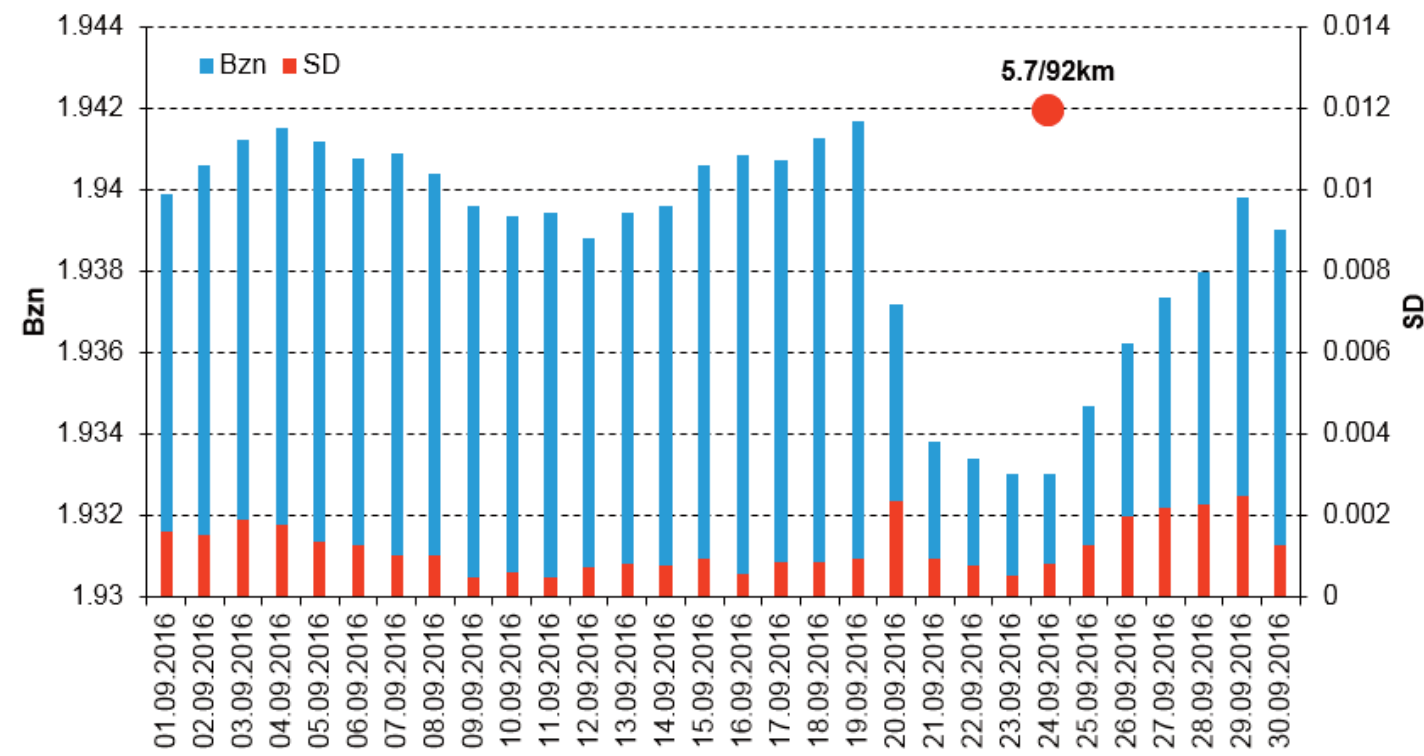

Figure 3. Daily distribution of the Bzn (blue bar) and SD (red bar) on September 2016; red full circle is Mw 5.7 earthquakes on September 24; ratio 5.7/92 is magnitude/hypocenter depth.

On the interval September 19-26, a significant anomalous domain of minimum, with values ranging from 1.933 to about 1.942 is observed on Bzn distribution (Figure 3). This anomaly is generated by the increased value of $\mathrm{B}^{\perp}$ (Figure 4), due to the high stress reached in Vrancea seismogenic volume, followed by the released electrical charges that are propagated along the 2-D geoelectric structure (CECA), before the onset of the Mw 5.7 earthquakes. 
Dragoș Armand Stănică et al.

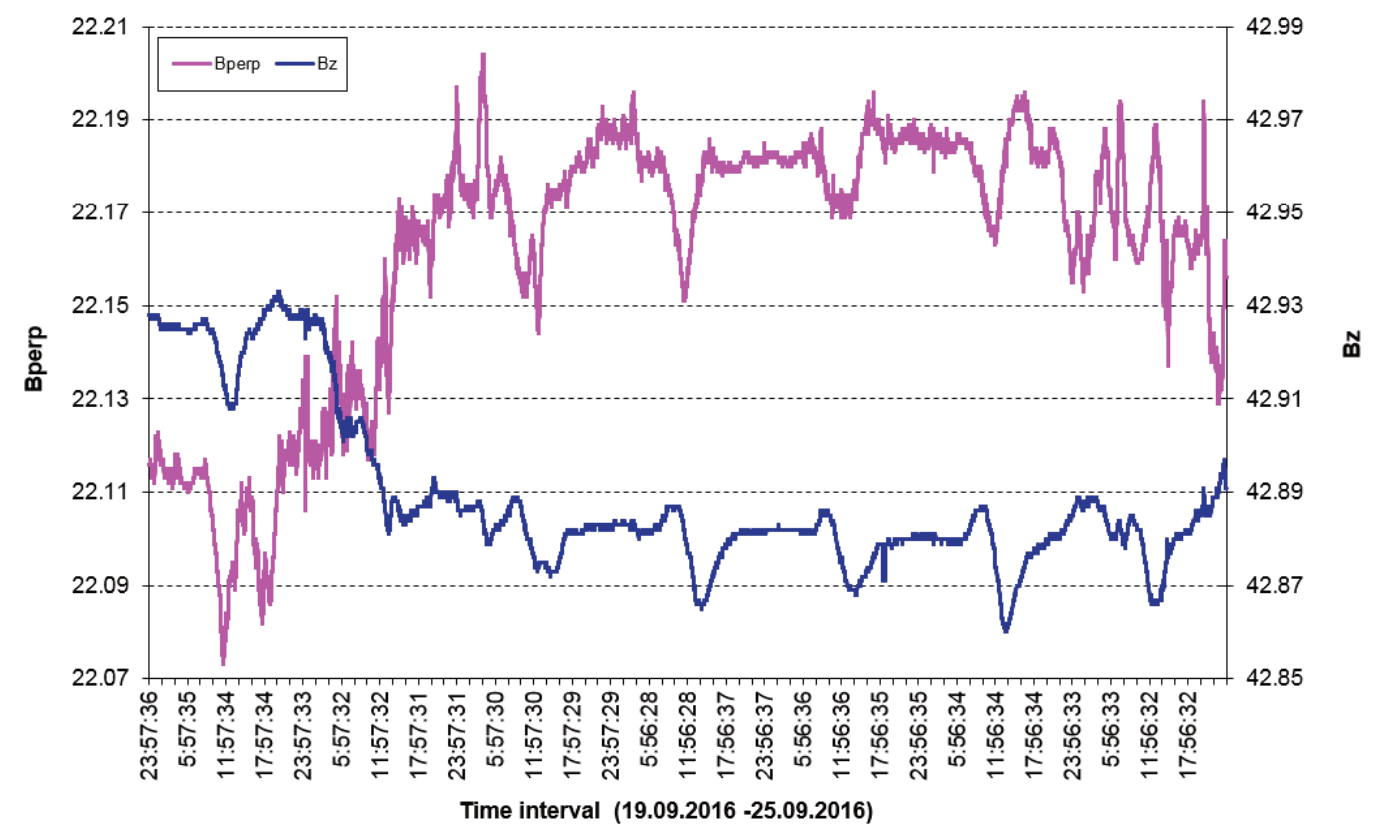

Figure 4. Bperp (red line) and Bz (blue line) time series of the geomagnetic field carried out on the time interval September 19-25, 2016 (here Bperp is $B \perp$ in text).

Figure 5 presents a graph with the Bzn*ABS time series which emphasizes a very large anomaly extended on the interval September 21-25. This anomaly with magnitude higher than 5-SD (red dashed line), represents a pre-seismic EM signature which starts on September 21, 3 days prior to the onset of Mw 5.7 earthquake.

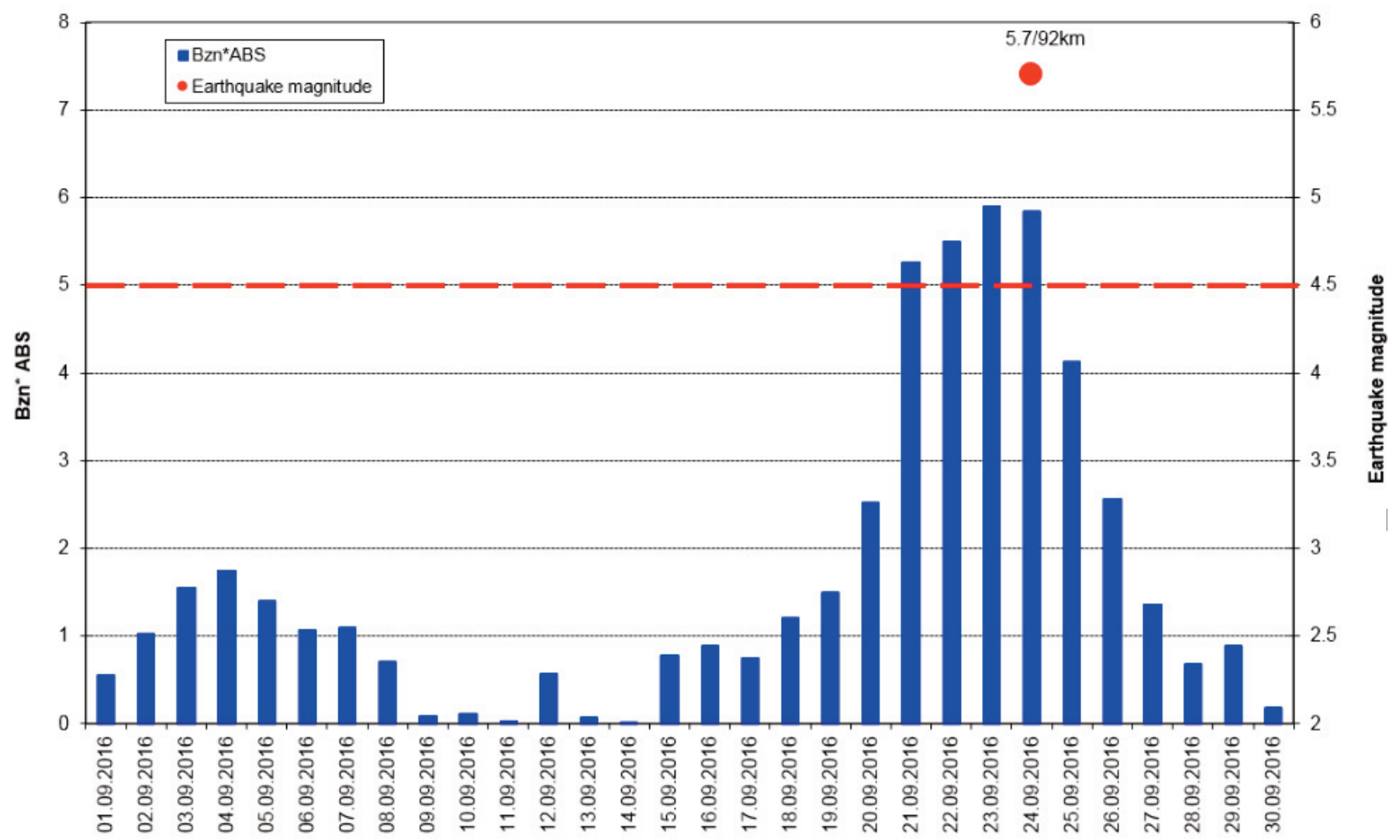

Figure 5. Bzn*ABS time series (ABS is absolute value) on September 2016; red full circle is Mw 5.7 earthquake on September 24; red dashed line is threshold for anomaly using SD. 
b) December 2016 with the subsequent graphs:

- Daily mean distributions of Bzn (Figure 6)

- Bzn* time series, represented in absolute values (Figure 7).

On the second interval, a very large anomalous domain of maximum with values ranging from 1.951 to 1.955 is also observed on Bzn distribution, placed on 10 days' interval in December 19-29 (Figure 6).

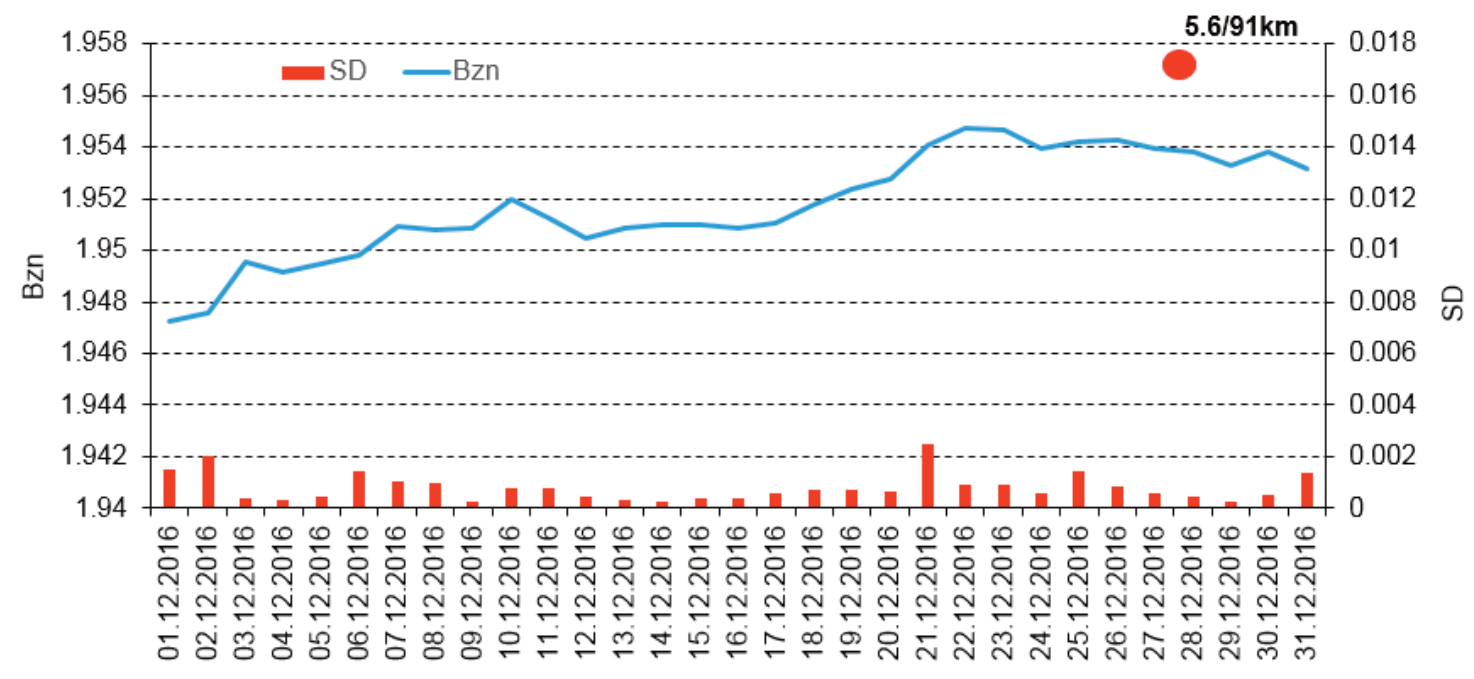

Figure 6. Daily mean distribution of Bzn (blue line) and SD (red bar) on December 2016; red full circle is Mw 5.6 earthquake on December 28; ratio 5.6/91km is magnitude/hypocenter depth.

The graph of Bzn* time series (Figure 7) emphasizes a very large anomaly of maximum which is extended on the interval December 19-29. This anomaly, with magnitude higher than 4-SD (red dashed line), which started on December 21, represents an EM precursor associated to the Mw 5.6 earthquake generated on December 28, 2016.

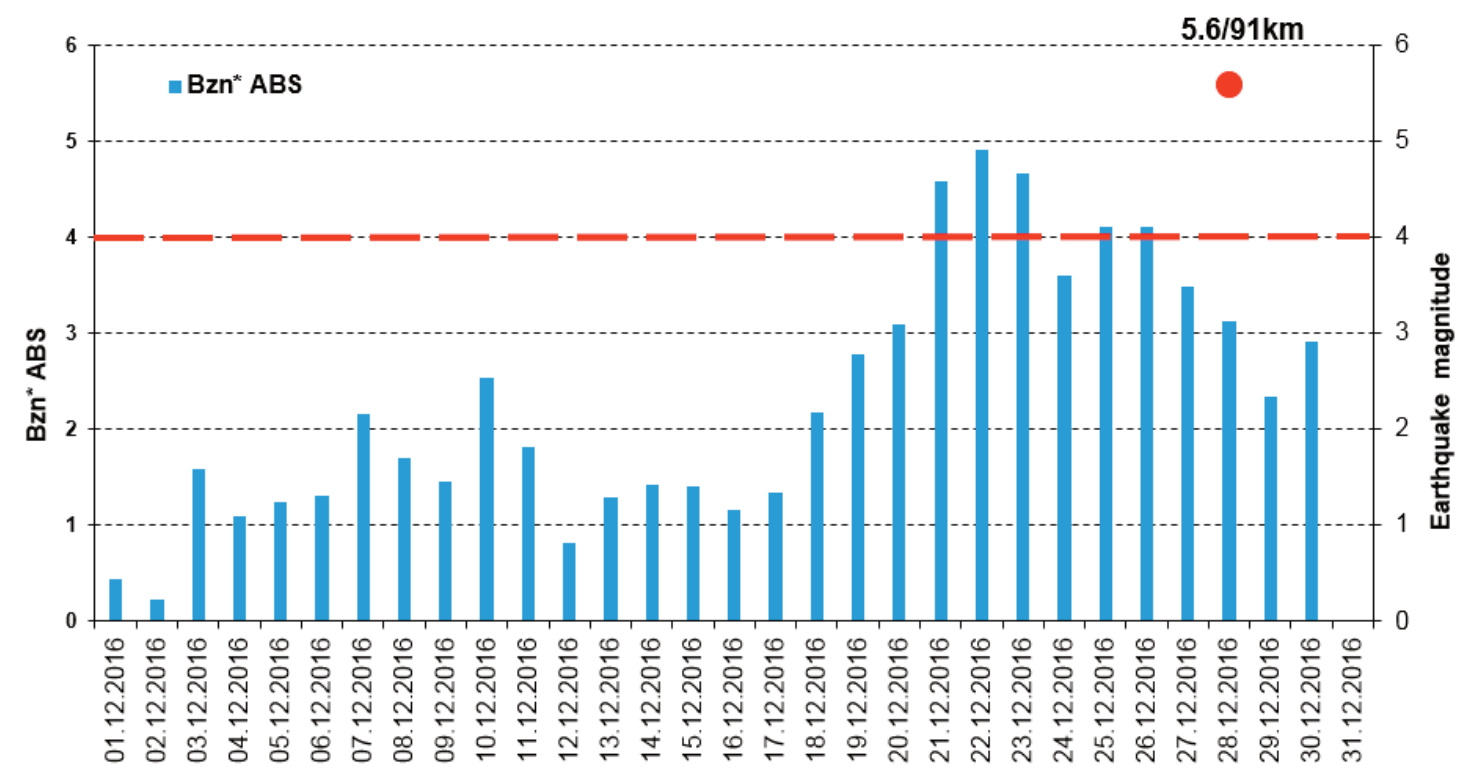

Figure 7. Bzn*ABS time series (blue bar) on December 2016; red full circle is Mw 5.6 earthquake on December 28, red dashed line represents threshold for anomaly using SD. 


\section{Dragoș Armand Stănică et al.}

\section{Conclusions}

In this paper, the ULF geomagnetic data recorded on September and December 2016 are analyzed with the aim to detect possible EM precursors associated with the Mw 5.7 and Mw 5.6 earthquakes and the following results are inferred:

- two very clear anomalous intervals of minimum, extended from September 19 - September 26 and December 19 - December 29, have been identified on Bzn distributions (Figure 3 and Figure 6);

- these anomalous domains are also well defined in the both Bzn* time series (Figure 4 and Figure 7) obtained after applying to the Bzn distributions a statistical analysis based on Equation (7);

- no doubt, the above information demonstrates that variability of Bzn observed in both situations are not randomly, these being two significant and reliable pre-seismic anomalous effects related to Mw 5.7 and Mw 5.6 earthquakes;

- the results obtained suggest that the pre-seismic anomalous intervals of the Bzn*, emphasized by using threshold for anomaly (red dashed line), have been triggered 3 days (Bzn* 5 in Figure 5) and, respectively, 7 days $\left(\mathrm{Bzn}^{*}=4\right.$ in Figure 7$)$ before the onset of the seismic events;

- as the work-station installed at IG-AR has specific programs for data processing, analysis and real time (daily) display such information on the institute website, this may be used as an early warning system able to provide useful information for the resilience improvement against the Vrancea intermediate depth earthquakes.

Taking into account that the major earthquakes may create considerable emergency situations, with disastrous consequences, it is very important to have reliable information prior to their occurrence, what this EM methodology already showed that it is possible. Therefore, any information related to a coming major earthquake, transmitted in time to the authorities responsible in this domain, can contribute to a better resilience and, consequently, to the prevention, management or decrease of the catastrophic risks.

Acknowledgements. The authors thank to the Institute of Geodynamics of the Romanian Academy for making electromagnetic data available to the user community. The authors are grateful to the anonymous reviewers for their comments and useful suggestions.

\section{References}

Constantinescu, L. and D. Enescu (1984). A tentative approach to possibly explaining the occurrence of the Vrancea earthquakes, Rev. roum. Geol., Geophys., Geogr., 28, 19-32.

CRC Group 461 (1999). Tectonics, Hazard and Risk Mitigation, 2-15.

Fan, G., T.C. Wallace and D. Zhao (1998). Tomographic imaging of deep velocity structure beneath the Eastern and Southern Carpathians, Romania: implication for continental collision. J. Geophys. Res., 103, 2705-2723.

Fitterman, D.V. (1978). Electrokinetic and magnetic anomalies associated with dilatant regions in a layered Earth, J. Geophys. Res., 83, 5923-5928.

Freund, F., A. Gupta, S. J. Butow and S. J. Tenn (1999). Molecular Hydrogen and dormant charge carriers in minerals and rocks, M. Hayakawa (editor), Atmospheric and ionospheric electromagnetic phenomena associated with earthquakes, Terra Sci. Publ. Comp., Tokyo, 839-871.

Freund, F. (2000). Time-resolved study of charge generation and propagation in igneous rocks, J. Geophys. Res. B, 105, 11001-11019.

Gufeld, I. L., G. A. Gusev, R. A. Lyutikov and M. I. Matveeva (1999). Seismic process as phase instability of lithosphere, M. Hayakawa (editor), Atmospheric and ionospheric electromagnetic phenomena associated with earthquakes, Terra Sci. Publ. Comp., Tokyo, 885-909.

Ismail-Zadeh, A. T., G. F. Panza and B. M. Naimark (2000). Stress in the descending relic slab beneath the Vrancea region, Romania, Pure Appl. Geophys., 157, 111-130

Koch, M. (1985). Non-linear inversions of local seismic travel times for the simultaneous determination of 3Dvelocity structure and hypocenters-application to the Vrancea zone, J. Geophys., 56, 160-173 


\section{Resilience improvement to Vrancea earthquake}

Morgunov, V. A. and S. A. Malzev (2007). A multiple fracture model of pre-seismic electromagnetic phenomena, Tectonophysics, 431, 61-72.

Nomikos, F., J. Vallianatos, S. Kaliakatsos, S. Sideris, and M. Bakatsakis (1997). Latest aspects of telluric and electromagnetic variations associated with shallow and intermediate depth earthquakes in South Aegean", Annali di Geofisica, XL, 2, 361-374.

Nomikos, K. and F. Vallianatos (1998). Electromagnetic variations associated with the seismicity of the frontal Hellenic Arc, Geologica Carpathica, 49/1, 57-60.

Oncescu, M. C. (1984). Deep structure of the Vrancea region, Romania, inferred from simultaneous inversion for hypocenters and 3-D velocity structure, Ann. Geophys., 2, 23-28.

Oncescu, M. C., V. Burlacu, V. Anghel and V. Smalbergher (1984). Three-dimensional P-wave velocity image under the Carpathian Arc, Tectonophysics, 106, 305-319.

Ouzounov, D., D. Liu, K. Chunli, G. Cevone, M. Kafatos, P., Taylor (2007). Outgoing long wave radiation variability from IR satellite data prior the major Earthquake, Tectonophysics, 431, 211-220.

Pinna, E., A. Soare, D. Stanica and M. Stanica (1992). Carpathian conductivity anomaly and its relation to deep substratum structure, Acta Geodaet. Geophys. Montanistica, 27(1), 35-45.

Sasai, Y. (1991). Tectonomagnetic modeling on the basis of the linear Piezomagnetic effect, Bull Earthquake Res Inst. Univ. Tokyo, 66, 585-722.

Spakman, W., S. van der Lee and R. van der Hilst (1993). Travel-time tomography of the European-Mediterranean mantle down to 1400 km, Phys. Earth Planet. Inter. 79, 3-14.

Stanica D., M. Stanica, L. Piccardi, E. Tondi, G. Cello (2004). Evidence of geodynamic torsion in the Vrancea (Eastern Carpathians), Rev. Roum. Geophysique, 48, 15-19.

Stanica, D. and D. A. Stanica (2010). Constraints on correlation between the anomalous behavior of electromagnetic normalized functions (ENF) and the intermediate depth seismic events occurred in Vrancea zone (Romania), Terr. Atmos. Ocean. Sci., 21(4), https://doi.org/10.3319/TAO. 2009.09.09.01 (T), 675-683.

Stanica, D. and D. A. Stanica (2011). Anomalous pre-seismic behavior of the electromagnetic normalized functions related to the intermediate depth earthquakes occurred in Vrancea zone, Romania, Nat. Hazards Earth Syst. Sci., 11, doi:10.5194/nhess-11, 3151-3156.

Stanica, D. and D. A. Stanica (2012). Earthquakes precursors, in "Earthquake Research and Analysis-Statistical Studies, Observations and Planning” Book 5, edited by: Dr. Sebastiano D’Amico, InTech open access publisher, Chapter 4, DOI:10.5772/2461D, 71-100.

Stanica, D, A., D. Stanica and N. Vladimirescu (2015). Long-range anomalous electromagnetic effect related to M9 Great Tohoku earthquake, Earth Sciences, 4(1), http://www.sciencepublishinggroup.com/j/earth, doi:10.11648/j. earth. 20150401.13, 31-38,

Stanica, D. A. and D. Stanica, J. Blecki, T. Ernst, W. Jozwiak, J. Slominski (2018). Pre-seismic geomagnetic and ionosphere signatures related to the Mw 5.7 earthquake occurred in Vrancea zone on September 24, 2016, Acta Geophys. 66, https://doi.org/10.1007/s11600-018-0115-4, 167-177.

Tramutoli, V., V. Cuomo, C. Filizzola, N. Pergola, C. Pietrapertosa (2005). Assessing the potential of thermal infrared satellite surveys for monitoring seismically active areas. The case of Kocaeli (Yzmit) earthquake, August 17th, 1999, Remote Sens. Environ. 96, 409-426.

Trifu, C. I. and M. Radulian (1989). Asperity distribution on percolation as fundamental of earthquakes cycle, Phys. Earth Planet. Inter., 58, 277-288.

Vallianatos, F. and A. Tzanis (1998). Electric current generation associated with the deformation rate of a solid: Preseismic and coseismic signals, Phys. Chem. Earth, 23/9-10, 933-939.

Vallianatos, F. and A. Tzanis (1998). A model for the generation of precursory electric and magnetic fields associated with the deformation rate of the earthquake focus" in M. Hayakawa (ed.), Seismic Atmospheric \& Ionospheric electromagnetic Phenomena, Terra Scientific Publishing Co., Tokyo.

Vallianatos and A. Tzanis (1999). On possible scaling laws between electric earthquake precursors (EEP) and earthquake magnitude, Geophys. Res. Lett., 26, 13, 2013-2016.

Vallianatos and A. Tzanis (2003). On the nature, scaling and spectral properties of pre-seismic ULF signals", Nat. Hazards Earth Syst. Sci., 3, 237-242.

Vallianatos, F, D. Triantis, A. Tzanis, C. Anastasiadis, I. Stavrakas, (2004). Electric earthquake precursors: from laboratory results to field observations", Phys. Chem. Earth, 29, 339-351. 


\section{Dragoș Armand Stănică et al.}

Varotsos, P., K. Alexopoulos, K. Nomikos, M. Lazaridou (1986). Earthquake prediction and electric signal, Nature, 322, 120.

Varotsos, P. A. (2005). The physics of seismic electric signals, TERRAPUB, Tokyo, 338.

Word, R.D., H.W. Smith and F. X. Bostick Jr. (1970). An investigation of the magnetotelluric tensor impedance method, Electronic Research Center, The University of Texas, Austin, Texas 78712, 242.

Wortel, M. J. R. and W. Spakman (1992). Structure and dynamics of subducted lithosphere in the Mediterranean region. Proceed. Konn. Ned. Acad. van Wetenschappen, 95, 325-347.

Yen H.Y., C. H. Chen, Y. H. Yeh, J. Y. Liu, C. R. Lin and Y. B. Tsai (2004). Geomagnetic fluctuations during the 1999 Chi-Chi earthquake in Taiwan, Earth Planet and Space, 56, 39-45. 